\title{
The day after tomorrow: financial repercussions of COVID-19 on systemic risk
}

\author{
David Vidal-Tomás $^{1} \cdot$ Rocco Caferra $^{1,2} \cdot$ Gabriele Tedeschi $^{2}$ (i)
}

Received: 13 April 2021 / Accepted: 2 November 2021 / Published online: 30 November 2021

(C) European Association for Evolutionary Political Economy 2021

\begin{abstract}
In this paper, we study the financial repercussions of COVID-19 and the effect of anti-epidemic measures on financial markets. By using a composite dataset containing stock market indices of 10 countries characterized by heterogeneous levels of contagion, the daily COVID-19 cases and the 108 more restrictive measures implemented to limit the virus from 31/12/2019 to 13/03/2020, we examine the emergence of financial systemic risk, its speed of propagation and the effectiveness of the policies implemented to curb it. On the one hand, the spread of contagion and its transmission on financial markets are investigated via a lagged cross-correlation analysis. Our results show the emergence of systemic risk characterized by a high speed of diffusion. On the other hand, an augmented $\operatorname{AR}(1)-\operatorname{EGARCH}(1,1)$ model is applied to examine the impact of anti-COVID-19 "policies on financial markets. We show that, regardless of the level of contagion, the restrictive measures are not able to contain the virus-induced investors panic in the first months of the epidemic.
\end{abstract}

Keywords COVID-19 Policy measures $\cdot$ Stock markets

JEL Classification G01 $\cdot$ G14 $\cdot$ G15 $\cdot$ G18

Gabriele Tedeschi

gabriele.tedeschi@gmail.com

David Vidal-Tomás

dvidal@uji.es

Rocco Caferra

rocco.caferra@gmail.com

1 Department of Economics, Universitat Jaume I. Department of Economics, Castellón, Spain

2 Department of Economics, Management and Business Law, University of Bari Aldo Moro, Bari, Italy 


\section{Introduction}

"Epidemics and financial crises share certain general features, such as the potential to spread globally in an increasingly interconnected world, characterized by rapid mobility of people, commodities, information and capital. Disease outbreaks may also induce market turbulence, necessitating catastrophic risk management." Peckham (2013a).

The speed of globalization in spreading catastrophic events was suspected even in 1889-during the "Asiatic Flu"-when, in approximately two months, the virus propagated from Russia to America due to "modern transport infrastructure"1. More than a century later-having a variety of data available-we can offer a deeper explanation of the dynamics of the contagion and its repercussion in the economic context.

Generally speaking, it is well known that the spread of epidemics has strong repercussions on markets and exacerbates financial contagion (Peckham 2013b) by generating a significant increase in prices co-movement due to systemic interconnection (see Pericoli and Sbracia 2003 and Bargigli and Tedeschi 2014, for an extensive review). ${ }^{2}$ A branch of economic literature closely linked with complexity science identifies in the self-reinforcing interaction among market participants the channel to propagate/reduce financial frictions which translate into booms followed by busts (see Grilli et al. 2020 for references on this topic). Typically, news, expectations and uncertainty about the future state of the world generate coordination phenomena or herding effects in traders' actions which affect stock market returns (see Wurgler and Baker 2007 and Chen et al. 2013). Different studies dealing with the emergence of financial contagion due to viruses spread, in fact, have found evidence of investors' overreaction, due to the arrival of news on virus outbreaks, able to destabilize financial markets (see Donadelli et al. 2016). In a similar vein, it has been shown that information on the health system resilience and the countries socio-economic stability has had a significant impact on stock markets both in the case of SARS in Asia and Ebola in Africa (Hanna and Huang 2004; Giudice and Paltrinieri 2017).

Given their historic recurrence ${ }^{3}$, pandemics can no longer be considered "black swan event" (Taleb 2007), highlighting the importance of the related risk management. Surely, they stress the governments' preparedness to deal with (un)expected and potentially disastrous shocks.

The recent vicissitudes due to the COVID-19 attack have reopened the debate on issues related to the systemic interconnectivity and on the measures to contain systemic risk. A rich and recent literature encouraged by the need to face the pandemic emergency has studied the virus socio-economic impact. Without wishing to be exhaustive, let us mention some papers dealing with the dynamics of the COVID19 diffusion (Alos et al. 2020; Kraemer et al. 2020; Buscema et al. 2020; Lee et al.

\footnotetext{
${ }^{1}$ https://en.wikipedia.org/wiki/1889_1890_pandemic

${ }^{2}$ Generally speaking, the collapse of the stock market is crucial in destabilizing the whole economic and financial system (Riccetti et al. 2016). This aspect exalts the relevance of the problem.

${ }^{3}$ https://www.newyorker.com/news/daily-comment/the-pandemic-isnt-a-black-swan-but-a-portent-of-amore-fragile-global-system
} 
$2020)^{4}$, its impact on financial markets (Albulescu 2020; Ramelli and Wagner 2020; Conlon and McGee 2020; Corbet et al. 2020; Akhtaruzzaman et al. 2021; Caferra and Vidal-Tomás 2021) and the measures/policies implemented to reduce its economic/financial spread (Gormsen and Koijen 2020; McKibbin and Fernando 2020; Kingsly and Henri 2020; Baldwin and di Mauro 2020; Collard et al. 2020). In this paper, we intend to contribute to the last two lines of research. Specifically, we ask the following questions: was there a correlation between the COVID-19 spread and the financial markets collapse? How have financial markets responded to the measures implemented to curb the contagion? In order to answer these points we use several daily time series concerning closing values of 10 stock market indices, daily numbers of COVID-19 infections and data on the restrictive measures implemented to control the contagion. The analysis, running from 31/12/2019 to 13/03/2020, is conduced on a heterogenous sample of countries which, during the investigated time period, show different levels of infections. Specifically, we collect data from Italy, Spain, Germany, France, China, South Korea where there is a medium/high number of infected people, and from Israel, the USA, Russia and the UK, where few infections are registered. From a methodological point of view two approaches are adopted. On the one hand, to study the synchronization between market indices dynamics and number of infections, we utilize the cross-correlation function. Although this technique is simple, the results are clear, highlighting the fast migration of the virus and its economic consequences. In line with other studies (see, for instance, Ramelli and Wagner 2020), we show that the pandemic quickly turned into a financial crisis. Interestingly enough, this is true not only for the highly infected areas but also for those COVID19 free. Moreover, the lagged cross-correlation analysis allows us to grasp the speed of the infection transmission. We show that the virus just needs 15 days to spread from East to West. Furthermore, once in Europe, the speed of diffusion exponentially increases and the financial collapse happens the day after the pandemic arrive in Italy. On the other hand, to analyze how financial markets respond to the antiCOVID-19 measures, we implement an augmented AR(1)-EGARCH(1,1) model. This approach, based on the Efficient Market Hypothesis, is traditionally used to capture the impact of exogenous shocks on financial returns (Karafiath 1988; Hansen and Lunde 2005; Malik 2011; Vidal-Tomás and Ibañez 2018; Zaremba et al. 2020). It assumes that new public information is incorporated in prices motions and, consequently, these reflect the traders reaction (such as pessimism and optimism waves) following the announcement. As the reader can appreciate later on, our results show a general unstoppable pessimism that is not reversed by anti-COVID measures in the most affected countries' stock markets. On the contrary, the stock exchanges of less infected countries remain indifferent to the measures, showing not to believe in their preventive effect.

One year later, in 2021, different studies employed a retrospective analysis of the mitigatory effect of implemented policy measures (see Haug et al. 2020). As stated

\footnotetext{
${ }^{4}$ An interesting approach using network theory to describe viruses spread is proposed (Brockmann and Helbing 2013).
} 
by the authors, drastic measures have been the "nuclear option" for COVID-19: on the one hand, the short-term negative expectations have been reversed by the long run effectiveness of restrictions in containing the contagion; on the other hand, different collateral consequences might have took place on the socio-economic system. Here, we prove evidence of the investors behavior in the early stage of the unstoppable virus outbreak, detecting if, even in the financial context, their short-term expectations have considered more the collateral effects (i.e., the sub-basement of the economic system) at the expense of the future benefits (i.e., the complete recovery of the system).

The rest of the paper is organized as follows. In Section 2, we describe the dataset. In Sections 2.1 and 2.2, we present the results on the spread of the virus and on the effectiveness of the measures applied to curb it. Specifically, we show the correlation analysis and the augmented AR(1)-EGARCH(1,1) model. Finally, Section 3 concludes.

\section{Data and descriptive analysis}

The goal of this paper is to analyze the financial contagion generated by the COVID19 spread and the effectiveness of the measures implemented to mitigate it. In this regard, three types of sources are used: (i) the daily closing values of 10 stock market indices characterizing countries with different levels of contagion. These indices, downloadable from Thomson Reuters Eikon, are: the MIB (Italy), the Ibex35 (Spain), the DAX30 (Germany), the CAC40 (France), the FTSE100 (UK), the S\&P500 (USA), the TA125 (Israel), the MOEX (Russia), the SHANGAI Composite (China) and the KOSPI (South Korea). All the selected countries, with the exception of Israel, the USA, Russia and the UK, where few infections are registered, report a medium/high number of infected people in the selected time window. The heterogeneity of the sample, and particularly the four counterfactual countries, allow us to understand if the financial contagion spreads regardless of the disease real attack, and the credibility of the preventive policies to contain it. (ii) The daily COVID-19 cases downloadable from the European Centre for Disease Prevention and Control database $^{5}$. (iii) A dataset containing the 108 more restrictive measures implemented to control the contagion. These country-specific measures include travel restrictions, policy measures and National emergencies Acts. The dataset is built by merging the detailed time-line provided by Wikipedia with the GardaWorld.com website. ${ }^{6}$

The analyzed time window runs from 31/12/2019 to 13/03/2020. The start and end dates correspond, respectively, to the day on which China officially announces the existence of the outbreak COVID-19 and the day after the characterization of this disease as "pandemic" by the World Health Organization. The end data (i.e., March 13) is set to capture only the "real" impact of the anti-COVID measures on financial markets and not the panic generated by the World Health Organization announcement.

\footnotetext{
${ }^{5}$ Data on the number of infected persons per day are available every week: https://www.ecdc.europa.eu/ en/publications-data/download-todays-data-geographic-distribution-covid-19-cases-worldwide.

${ }^{6}$ The dataset is included in Appendix 1.
} 
The time series of the stock index prices and returns are shown in Fig. (1). As expected, the Chinese financial market is the first to suffer from the impact of COVID-19. However, due to the closure of the Chinese stock market from 23/01/2020 to 03/02/2020 for the Lunar New Year holiday, the drop in prices occurs after the onset of the disease (see point "a" in the figure). The shock wave takes about 15 days to hit the other markets and is particularly aggressive in Italy. In Fig. 2, we report the number of new daily cases of infections (blue bar) and the date when the measures to contain the contagion are implemented (dashed line). ${ }^{7}$ As the reader can observe, most of the countries begin to apply massively anti-contagion measures only once the infection starts in their own territory. Two interesting exceptions are Russia and Israel where strong prevention measures are observed. On the other hand, the behavior of the UK is unusual. Here we observe some preventive measures, related to "flight routes suspensions," but any intensification of these measures when the infection appears on the national territory.

\subsection{The spread of financial contagion}

In this session, we study the spread of contagion and its transmission on financial markets. Considering China (Italy) as the worldwide (Western) trigger point, we analyze (i) the cross-correlation between the growth rate of the number of new daily infections in China (Italy) and the lagged growth rate of the number of infection in the other countries and (ii) the corresponding cross-correlation between the returns of stock market indices (see Chatfield 1994 and Shen and Zheng 2009, for a similar approach). With this methodology, we do not aim at studying the causality effect between COVID-19 and market movements, but we would infer, considering each pairwise couple of countries i) the cross-country propagation time of both virus and financial shock, and ii) the synchronization of the two mentioned events, observing the alignment between the peaks of correlation of COVID-19 cases and market indexes. Results are reported in Fig. 3. As the reader can observe, the correlations show similarities in the spread of the contagious and in the relation between the indices. Before the onset of the infection (i.e., up to lag 0), all returns time series were already slightly correlated. This fact reflects the well-known synchronization in the financial markets also known as globalization (see Saunders and Cornett 2014 and Alfarano et al. 2019). As we can see, the COVID-19 outbreak in China generates a "desynchronization" between the return series due to the Chinese market collapse. Obviously, also the correlation between the numbers of infections is negative in the first positive-lags - China, in fact, is the first country to be affected by the disease.

\footnotetext{
${ }^{7}$ It is worth mentioning that, later in time, some doubts arose on the accuracy of both (i) early-stage daily cases data, since different (criticized) countries-specific detection methods were adopted (Iacobucci 2020), and (ii) the detection of number of deaths, since different problems arose in properly identifying the causality between COVID-19 and deaths on the light of other potential omitted variables/diseases (Brown 2020; Woolf et al. 2020). In this case, we do not enter the merit of the calculation method employed, and we limit ourselves in considering the high trust level that readers can have on the authoritative data source announcing virus contagion. We opt for daily cases as the raw proxy of virus diffusion and, consequently, as the early-warning indicator of potential stress of the health (and then economic) system. Furthermore, we cannot use the number of deaths since Russia and Israel did not record any case in the selected period.
} 


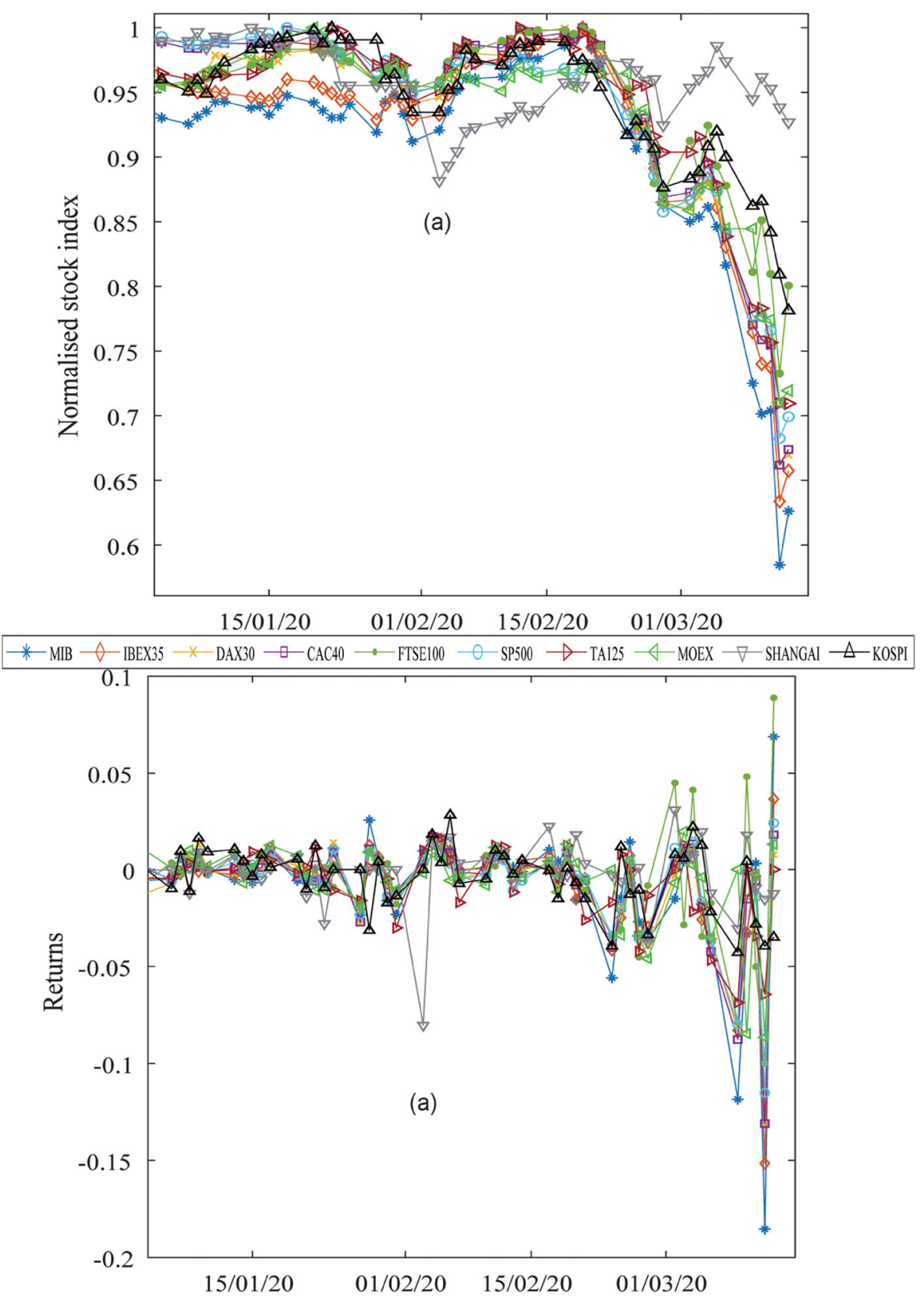

Fig. 1 Normalized stock index prices and returns from 31/12/2019 to 13/03/2020. Indexes are normalized using their maximum value 

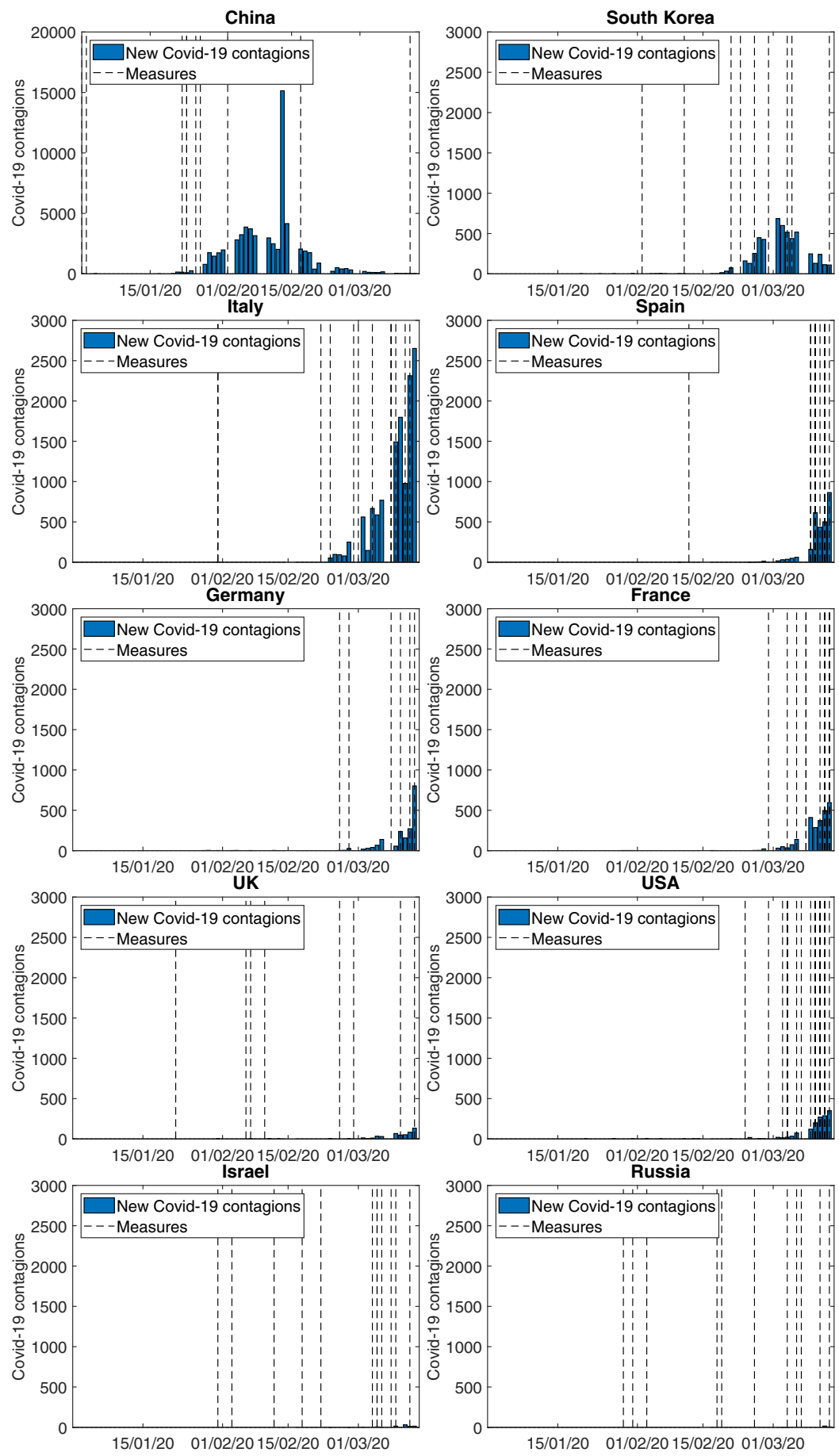

Fig. 2 Number of new daily infections (blue bar) and the date of anti-contagion measures (dashed line) 

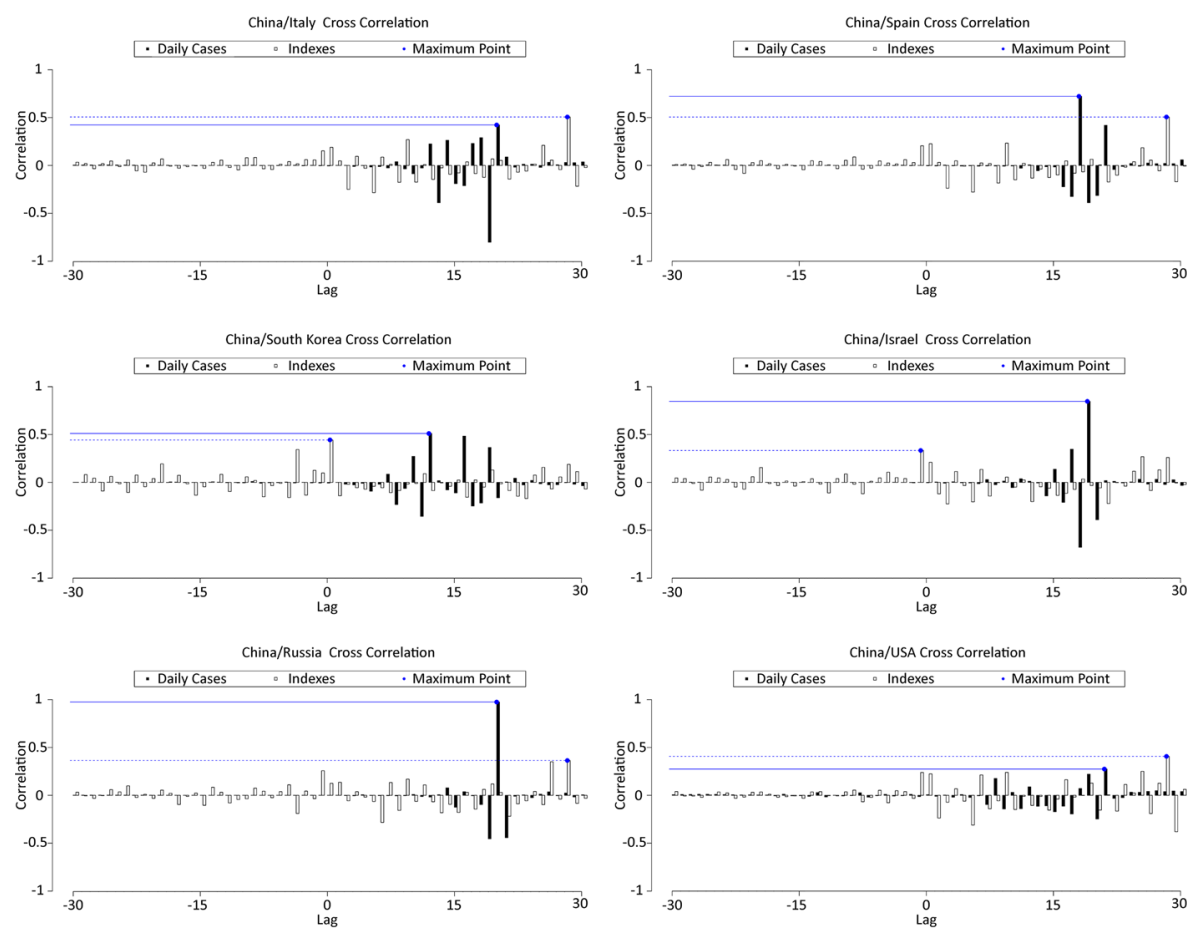

Fig. 3 Cross-correlations with respect to Chinese values. Black bars represent the cross-correlation between the growth rate of the number of new daily infections; white bars shows the cross-correlation between returns of the stock indexes. The maximum value reached by the correlation of infections (indexes) is identified by a solid (dashed) blue line

About 15-20 days after the outbreak of the COVID-19 in China, the infection spreads to other countries as shown by black bars in Fig. 3. It is in the few days following the spread of the pandemic that we re-observe a strong realignment between the financial series confirming the interconnection among markets and the onset of the systemic risk. The relevance of the economic interconnection and the systemic risk becomes more evident considering the chinese relationship with Israel and South Korea. In these cases, the financial market collapse is synchronized (at $t=0$ ) with the Chinese stock market. It can be argued that the economies of these countries are highly interconnected and then, despite the delay of the cross-country spread of contagion, the financial repercussions are instantaneous. In our highly globalized world, the crosscorrelations evidence that approximately 15-20 days have been needed to spread the pandemic and just 20 days to bring down all markets. Obviously, considering Italy as the trigger point and, therefore, considering the pandemic spread since its arrival in Europe, the whole process speeds up even further and, the "previous 15-20 days" become the "day after tomorrow," as shown in Fig. 4 where the highest correlations between the number of new daily infections in Italy and the lagged number of infection in other countries (black bars) ${ }^{8}$, and between the MIB and the other stock indexes

\footnotetext{
${ }^{8}$ Results on the correlations between other countries are omitted, but similar in spirit.
} 

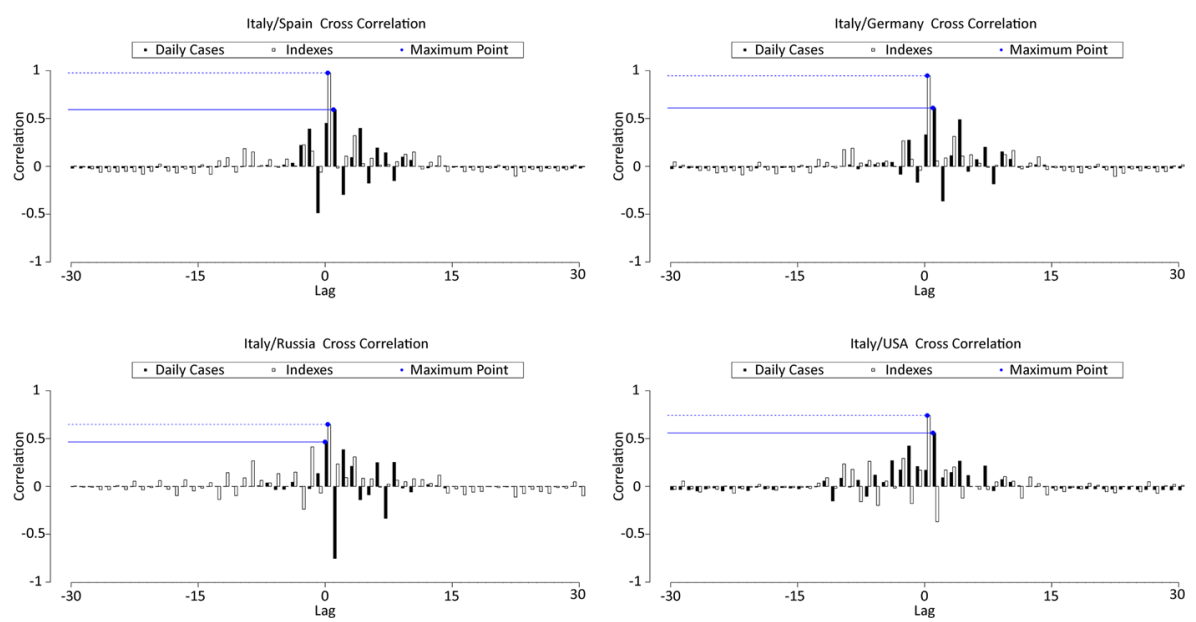

Fig. 4 Cross-correlations with respect to Italian values. Black bars represent the cross-correlation between the growth rate of the number of new daily infections; white bars shows the cross-correlation between returns of the stock indexes. The maximum value reached by the correlation of infections (indexes) is identified by a solid (dashed) blue line

(white bars) are found at lags 1 and 2. Here, it is possible to observe how the correlation between the daily changes of cases starts to increase before the joint financial collapse (i.e., before the point of highest correlation among the financial returns).

\subsection{COVID-19 flood and disaster management}

In this section, we analyze the financial markets reaction to policy measures implemented to deal with the virus spread. To this end we apply the augmented AR(1)EGARCH(1,1) model (Karafiath 1988; Hansen and Lunde 2005; Malik 2011), which is traditionally used to examine the effect of different shocks affecting financial markets, such as good or bad news, policy measures and calendar effects (Aharon and Qadan 2019; Malik 2011; Vidal-Tomás and Ibañez 2018; Zaremba et al. 2020). ${ }^{9}$ The model specification is:

$$
\begin{gathered}
r_{i, t}=\mu+\beta_{1} r_{i, t-1}+\beta_{2} p m_{i, t}+\varepsilon_{i, t}, \quad \varepsilon_{i, t}=h_{i, t} z_{i, t}, \quad z_{i, t} \sim i . i . d . N(0,1), \\
\log \left(h_{i, t}^{2}\right)=\omega+\alpha\left|\varepsilon_{i, t-1} / h_{i, t-1}\right|+\gamma\left(\varepsilon_{i, t-1} / h_{i, t-1}\right)+\rho \log \left(h_{i, t-1}^{2}\right),
\end{gathered}
$$

where $r_{i, t}$ denotes the return of the stock index $i$ at day t, $p m_{t}$ the dummy variable identifying security measures, $\varepsilon_{i, t}$ the error term, $z_{i, t}$ the white noise and $h_{i, t}^{2}$ the conditional variance given by the EGARCH model. Moreover, in relation to the conditional variance, $\alpha$ represents the magnitude of the variance shock, $\gamma$ the sign effect and $\rho$ the persistence of the shock volatility. Finally, the parameters $\beta_{1}$ and $\beta_{2}$ capture the market trend and the effect of the anti-COVID security measures, respectively.

\footnotetext{
${ }^{9}$ Given that the financial literature provides scholars with many different GARCH models able of capturing asymmetric effects, it could be also possible to use other alternatives such as GJRGARCH or APARCH models.
} 
Table $1 P$-values of pre- and post-estimation tests

Pre-estimation tests MIB IBEX35 DAX CAC40 FTSE100 SP500 TA125 MOEX SHANGAI KOSPI

\begin{tabular}{lcccccccccc}
\hline $\operatorname{Arch}(5)$ & 0 & 0 & 0 & 0 & 0 & 0 & 0 & 0 & 0.98 & 0.15 \\
\hline Post-estimation tests & MIB & IBEX35 & DAX & CAC40 & FTSE100 & SP500 & TA125 & MOEX SHANGAI KOSPI \\
\hline $\operatorname{Arch}(5)$ & 0.90 & 0.53 & 0.98 & 0.82 & 0.77 & 0.42 & 0.25 & 0.44 & - & - \\
$Q^{2}(10)$ & 0.75 & 0.98 & 0.49 & 0.99 & 0.95 & 0.44 & 0.78 & 0.19 & - & - \\
\hline
\end{tabular}

In order to capture the immediate effect (i.e., the impact of each policy on the announcement day) and the gradual effect (i.e., the reaction including the rumors of the day before and the consequence of the day after) of the anti-COVID measures, we consider two measures of abnormal returns in the model (1). Considering the day of the announcement $t$, we include a dummy $p m_{t}$ equal to 1 on the announcement day $t$ (and 0 otherwise) to calculate the abnormal returns in that day $\left(A R_{0}\right)$. In the other specification, $\mathrm{pm}_{t}$ is equal to $\frac{1}{3}$ on days $t-1, t$, and $t+1$ (and 0 otherwise), and we measure the cumulative abnormal returns on those days $\left(C A R_{(-1,1)}\right) .{ }^{10}$

The pre-estimation test on the time series returns and post-estimation tests for the $\operatorname{AR}(1)-E G A R C H(1,1)$ model are shown in Table 1 . As the reader can observe, in the pre-estimation test, no ARCH effect emerges in Chinese (Shangai) and South Korean (KOSPI) indices, and therefore these two time series are removed from the sample. ${ }^{11}$ As regards the post-estimation test, instead, we observe that all other indices are estimable with the chosen model. Interestingly enough, we also observe that most of the indices are characterized by a statistically significant presence of asymmetry $(\gamma)$, which supports the choice of the EGARCH model as a good candidate to represent the dynamics of the conditional volatility (Hansen and Lunde 2005). ${ }^{12}$

Let us now present the estimation of the $\operatorname{AR}(1)-\operatorname{EGARCH}(1,1)$ model parameters, that is $\beta_{1}$ and $\beta_{2}$. Results are reported in Table 2, where the values of the parameters resulting from model estimation in the $A R_{0}$ and $C A R_{(-1,1)}$ specification are shown. Firstly, as expected, the $\beta_{1}$ parameter in the $A R_{0}$ specification is not statistically significant for all the stock returns except for the Russian one (i.e., MOEX). This result on asset returns has been widely documented (Cont 2001; Tedeschi et al. 2009) and is often cited as support for the "Efficient Market Hypothesis" (Fama 1965). By observing the lagged model specification (i.e., $C A R_{(-1,1)}$ ), the estimated value of the $\beta_{1}$ parameter, while remaining in many cases not statistically significant, shows a general mean reversal dynamics.

\footnotetext{
${ }^{10}$ Unfortunately, it is not possible to insert a regressor estimating and isolating the effect of the growth rate of infection, given the imperfect collinearity between cases and COVID-19 measures. For instance, the correlation between USA cases and COVID-19 policies is around 70\%. Considering that policies were generally adopted in correspondence of an increase in events, we decided to use a single proxy to capture the "COVID effect" on markets

${ }^{11}$ At any rate, we include the results regarding Chinese (Shangai) and South Korean (KOSPI) indices in Appendix 2.

${ }^{12}$ Results on the conditional variance are shown in Appendix 2.
} 


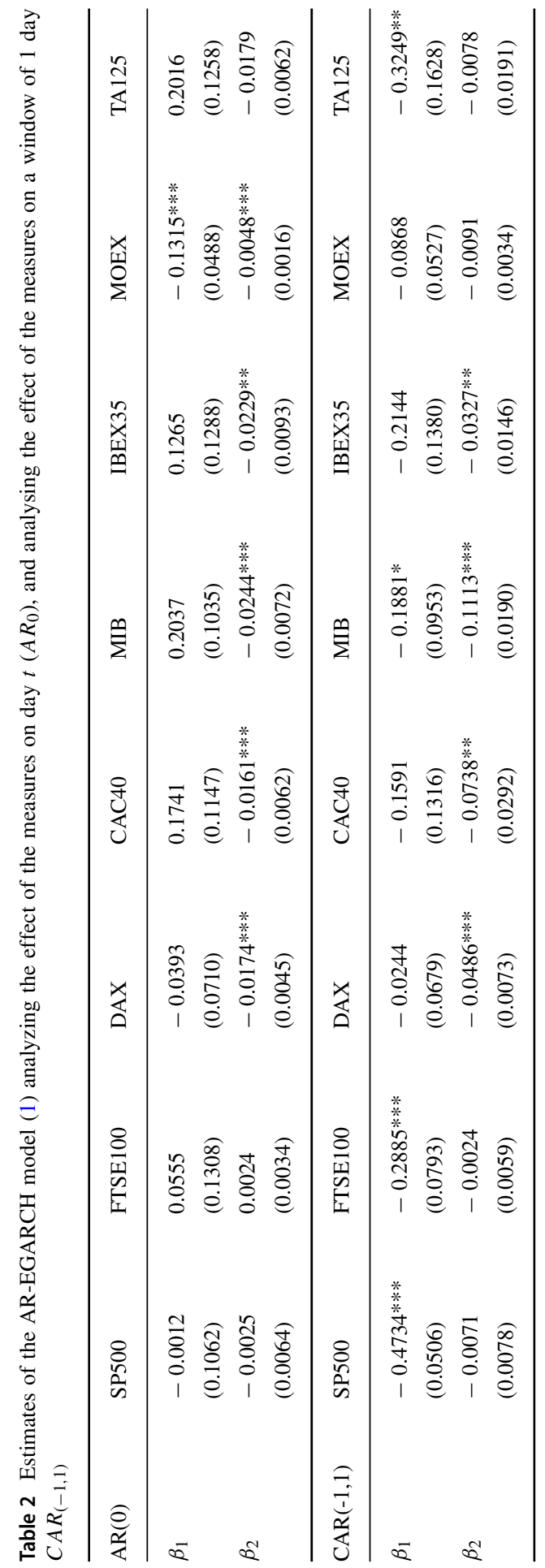


On the other hand, as regards the estimated value of the parameter capturing the effect of anti-COVID measures on financial returns, $\beta_{2}$, we observe a clear separation between infected and (apparently) less infected countries, i.e., Italy, Spain, Germany and France, vs the UK, the USA, Israel and Russia. In both model specifications we have a statistically significant negative effect of policies on the financial returns of those countries most affected by the pandemic. Moreover, interestingly enough, the value of the parameter estimated with the lagged model specification (i.e., $\left.C A R_{(-1,1)}\right)$ always displays a statistically more negative impact than that estimated with the $A R_{0}$ one. This fact has a double interpretation. On the one hand, it suggests that the implemented measures are anticipated by the markets. On the other hand, the fact that poorly affected countries are statistically insensitive to anti-COVID policies strengthens the hypothesis of their perceived preventive uselessness.

\section{Concluding remarks}

Our analysis has shown that the COVID-19 attack on financial markets brought back to light the well-known phenomenon of systemic risk. In fact, we have proven that the onset of the virus has caused a sudden and simultaneous fall in financial markets, possibly due to the strong interconnections among them. Whereby the pandemic has taken about 15 days to spread from eastern countries to western one, once in Europe, the contagion has hit almost all markets in unison.

Moreover, our retrospective analysis shows how policy measures did not calm down investors panic. At least in the short run, the collateral components of such measures were predominant in shaping expectation. Although our results are still quite preliminary, they capture two interesting points. The first concerns the direction of the attack. The virus-induced economic and financial crisis highlights the increasingly complex systemic interaction which dominates in modern socio-economic systems. The second key point is that, as in the previous crisis, long-term oriented policy measures can not lessen short-term financial pessimism.

Plausibly, the coordination failure of country-specific policy led to a delay in the containment of the initial contagion, since, as shown, most of the countries begun to apply massively anti-contagion measures only once the infection started in their own territory, without anticipating the virus intrusion. In the era of globalization, the pandemic outbreak is more likely to be a common necessary evil rather than an isolated country-specific problem. Once more the systemic risk has been faced in an uncoordinated and unidirectional way without applying the science of complexity, which recommends studying the socio-economic system starting with the coevolution of its sub-systems and not breaking it down into disjointed, non-communicating sub-spheres (see Tedeschi et al. 2020 for further references). Once again, the past experience quickly fell into oblivion and Mr.Trichet' s words went unheard: "the key lesson we would draw from our experience is the danger of relying on a single tool, methodology or paradigm. Policy-makers need to have input from various theoretical perspectives and from a range of empirical approaches... we need to develop complementary tools to improve the robustness of our overall framework." 


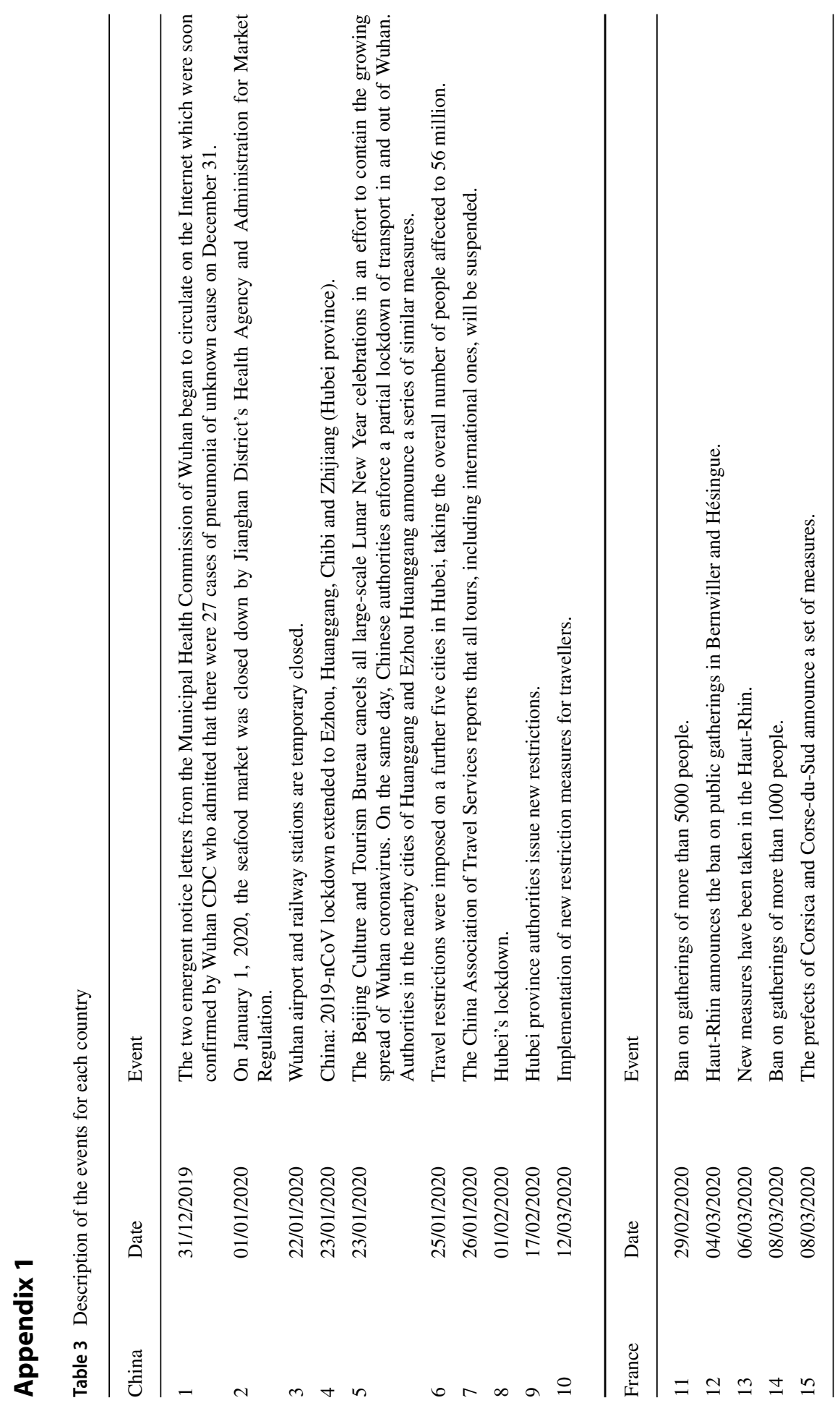




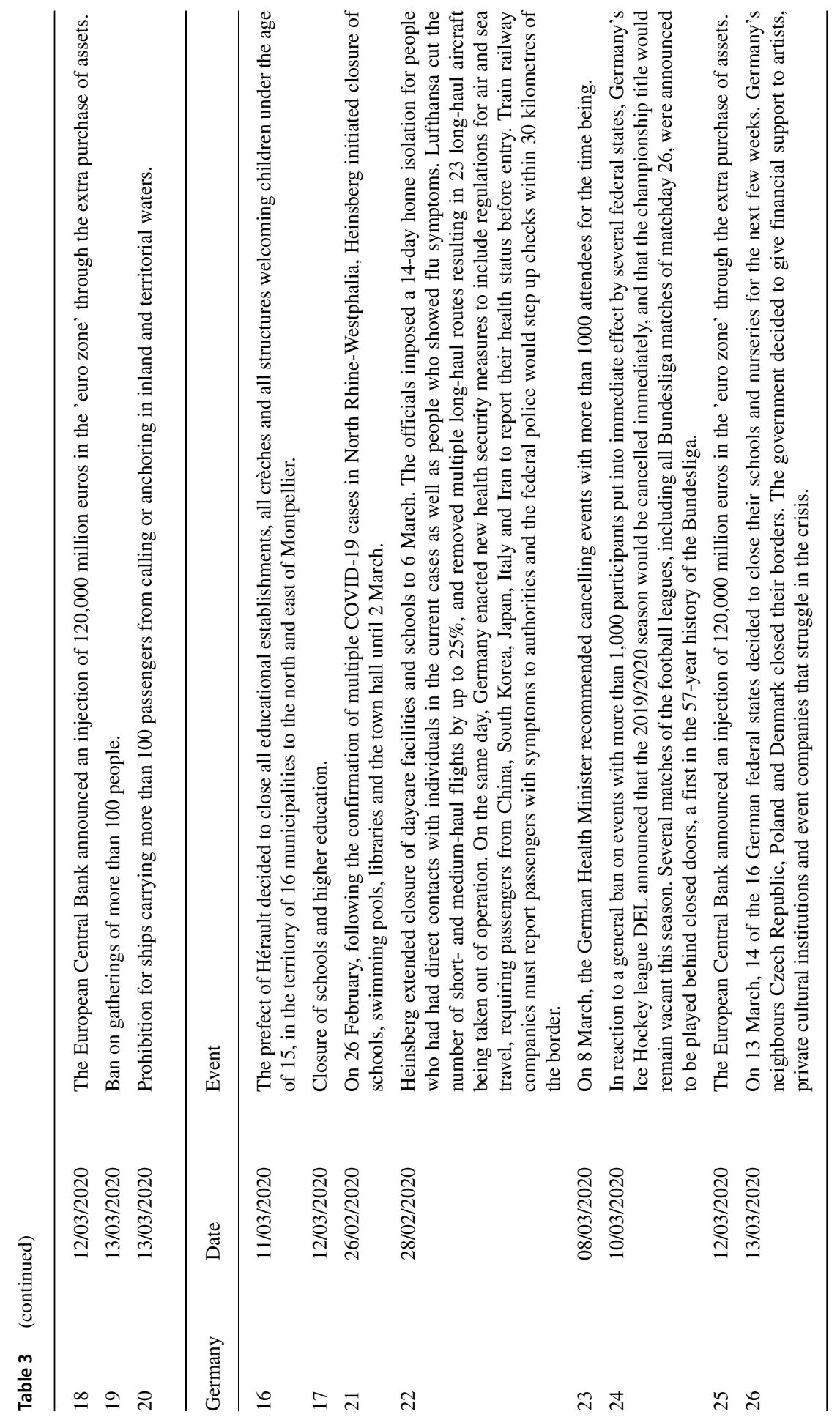




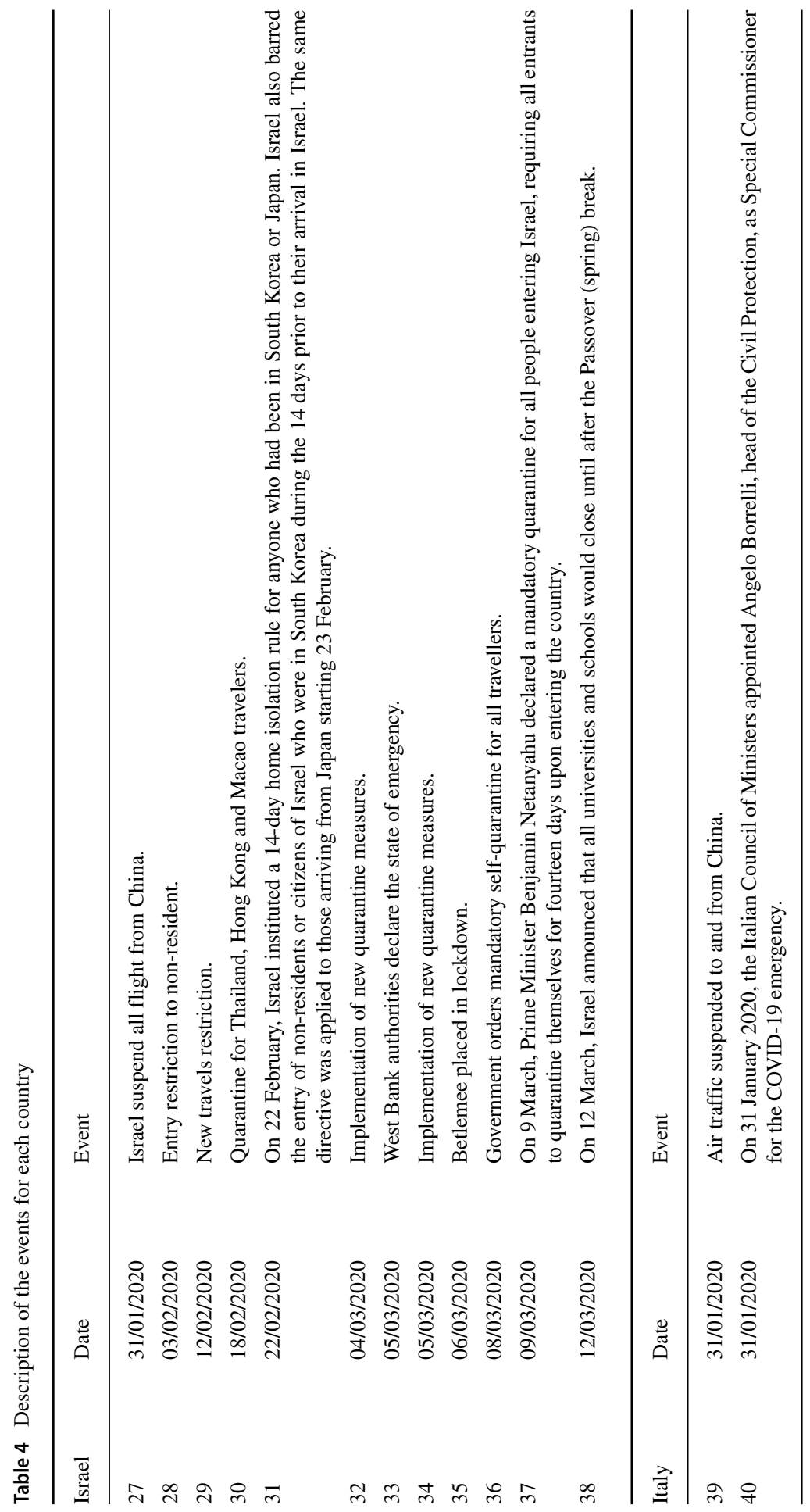




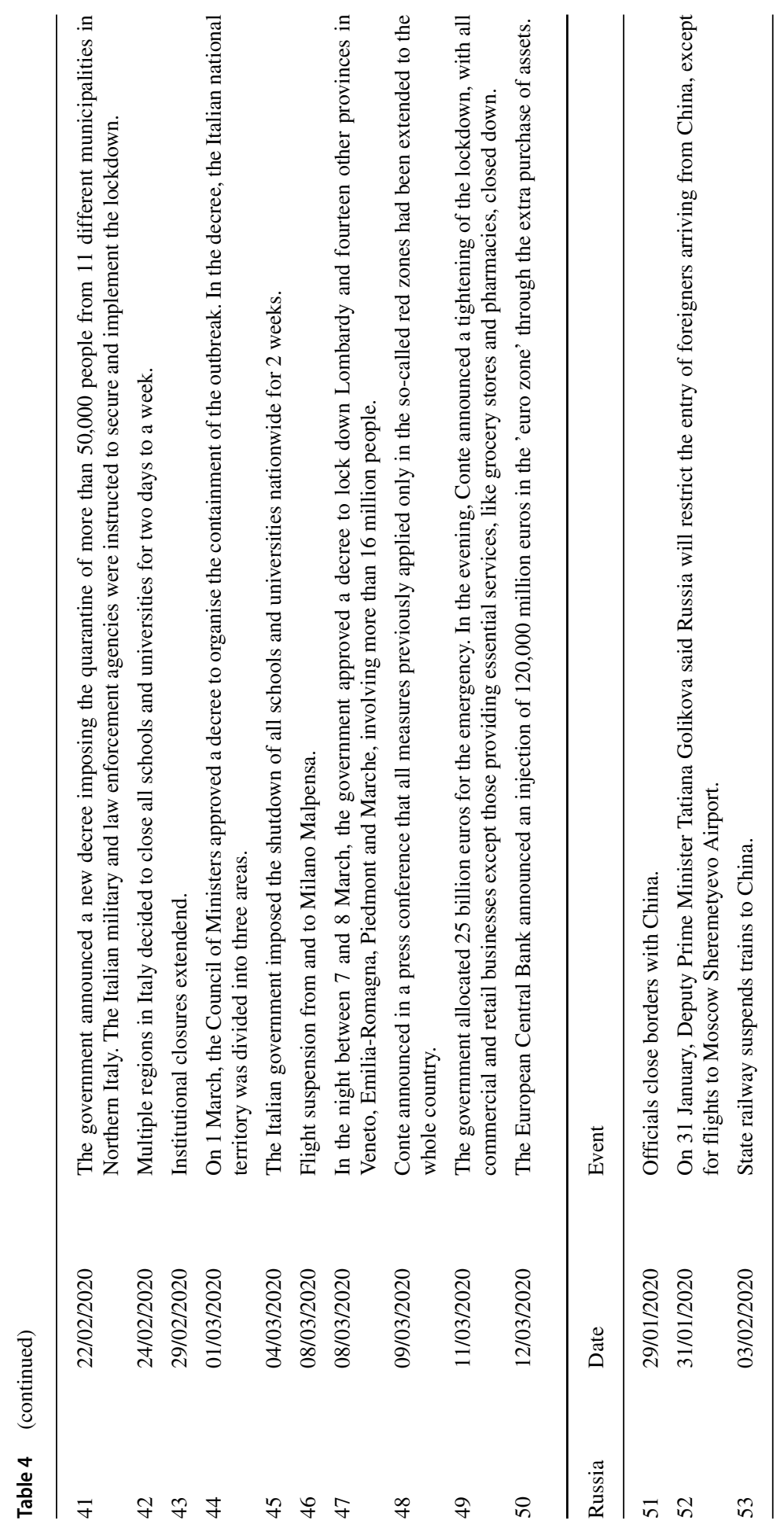




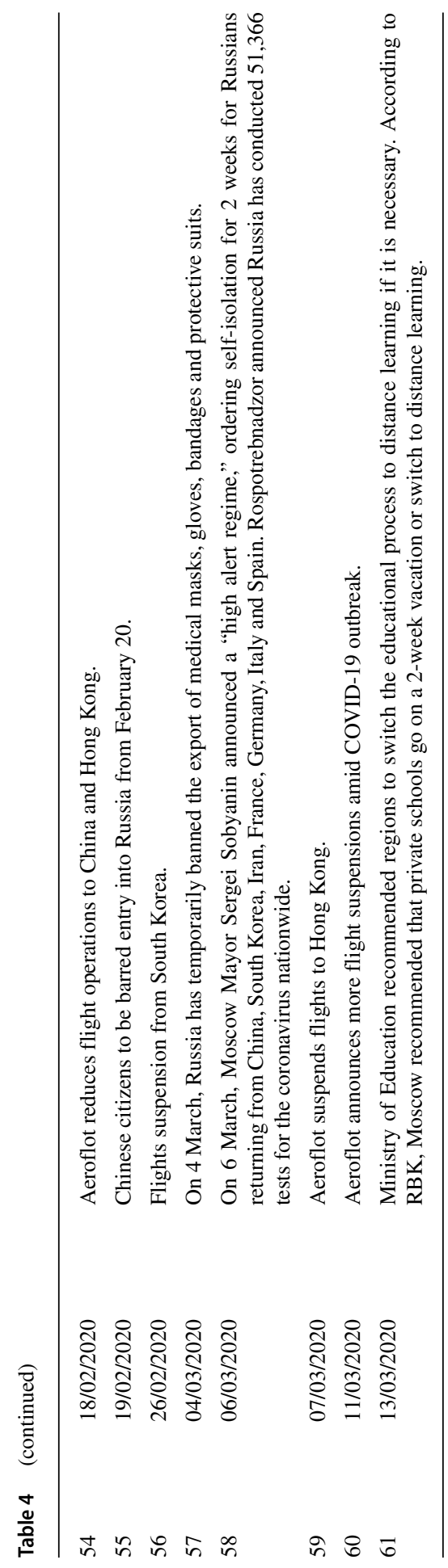




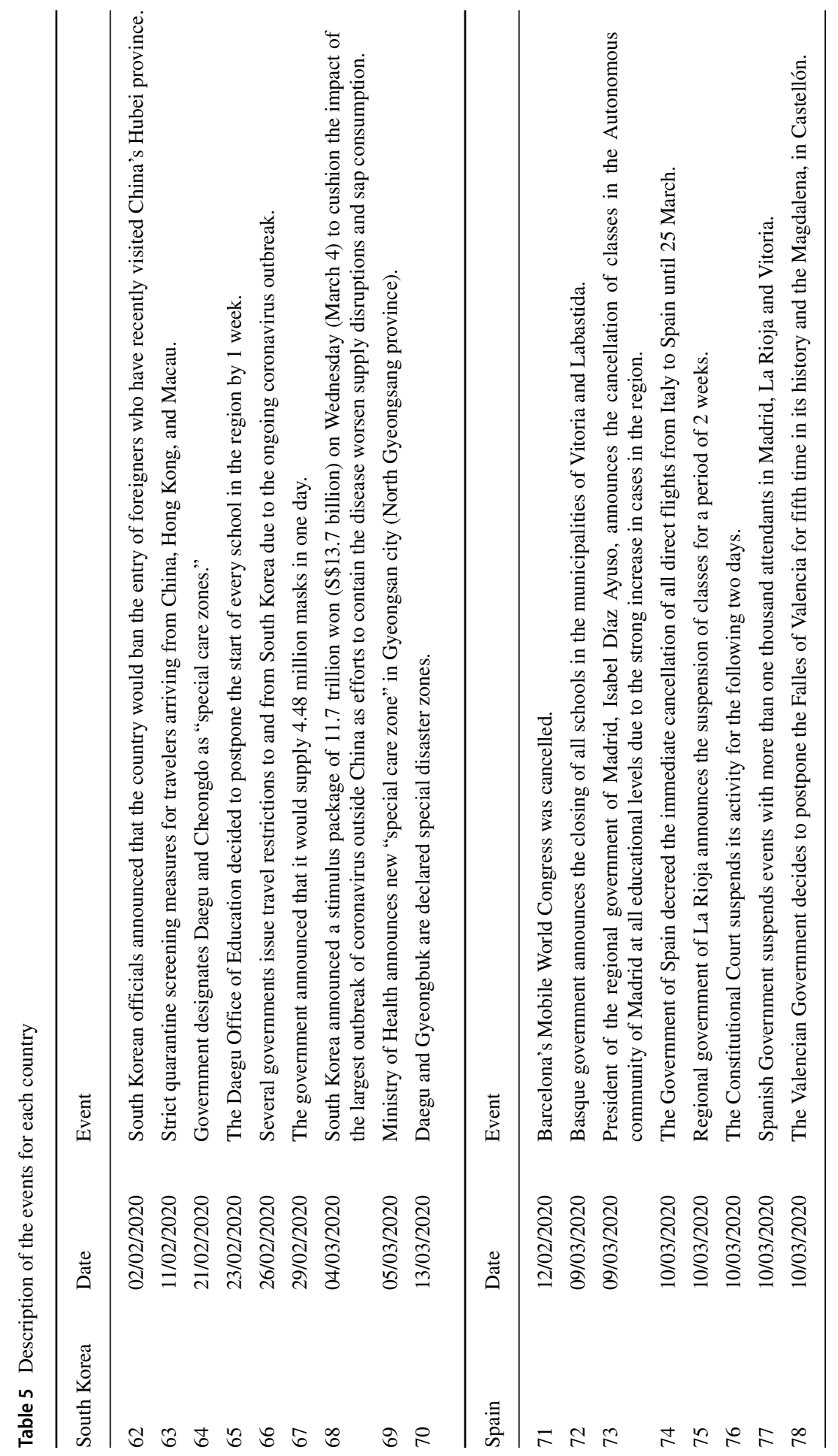




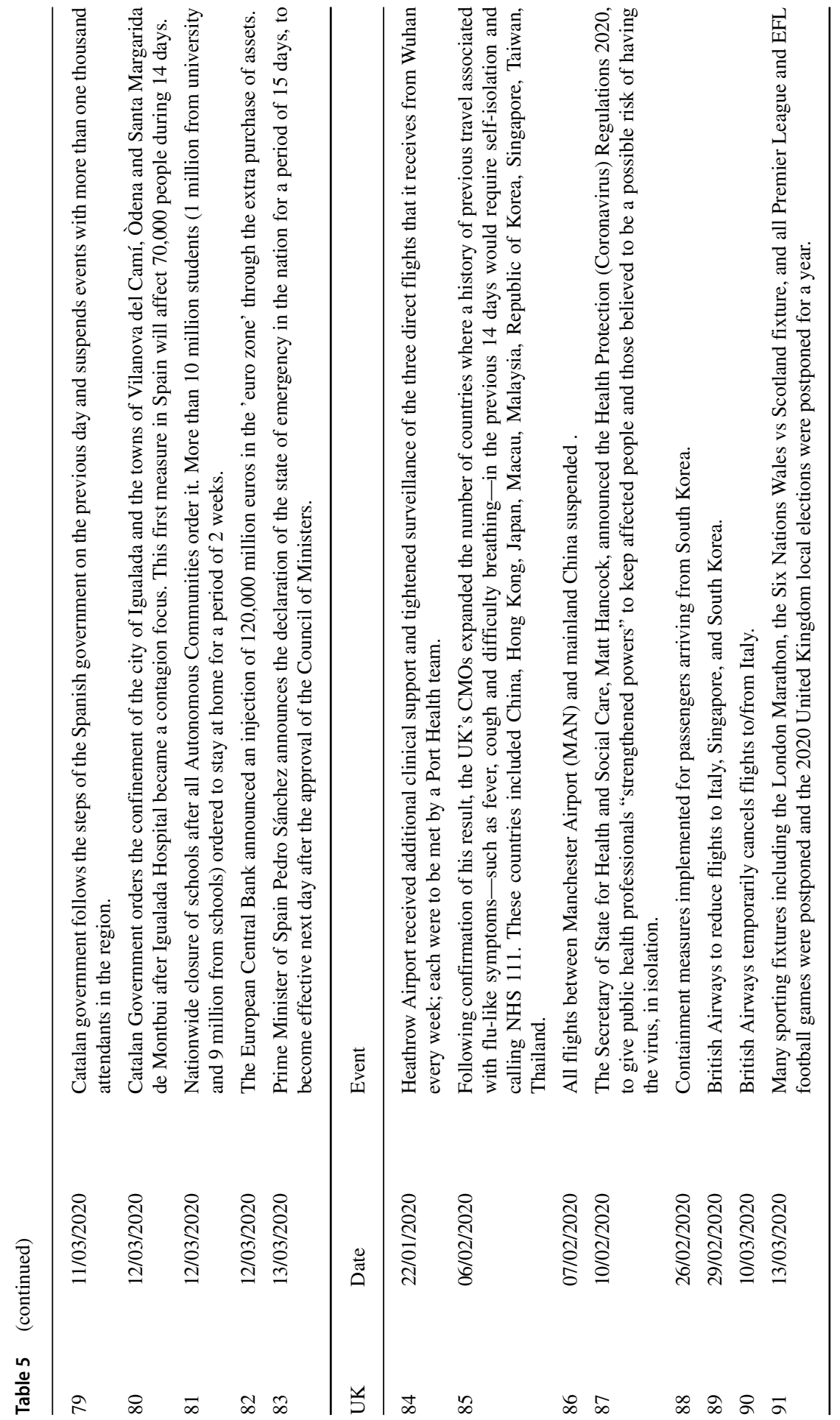




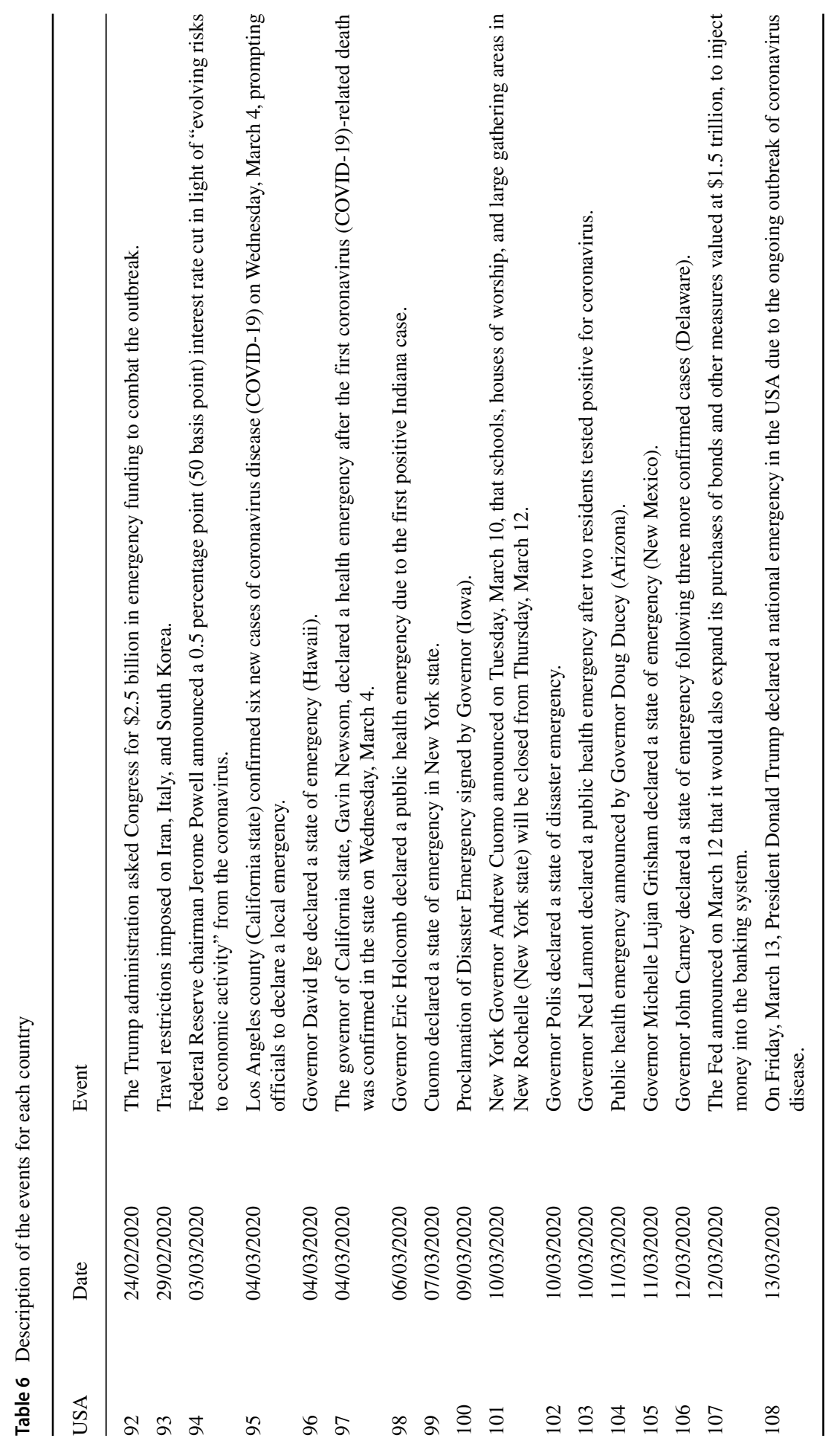




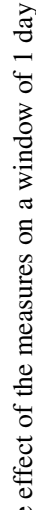

胥

章

르

$\stackrel{3}{3}$

글

항

章

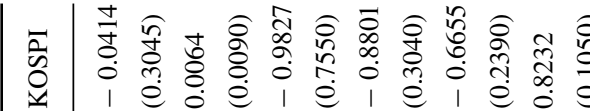

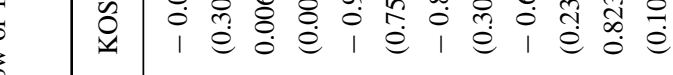

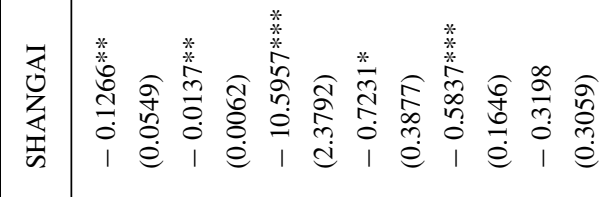

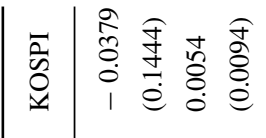

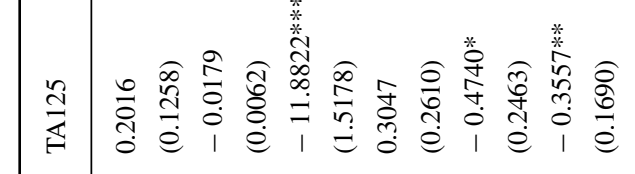

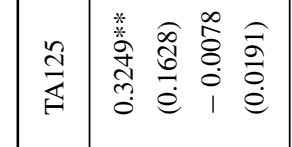

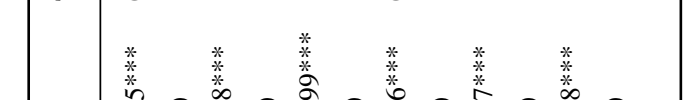

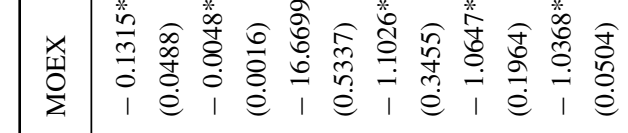

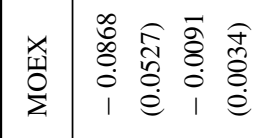

类* * * * *

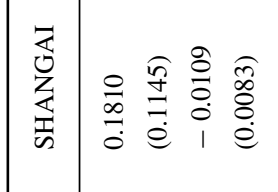

$\stackrel{0}{5}$

范

$\stackrel{0}{g}$

.

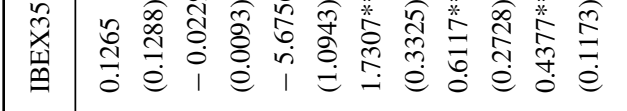

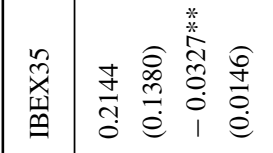

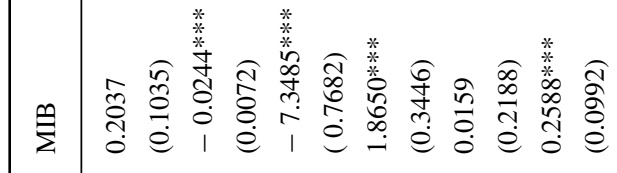

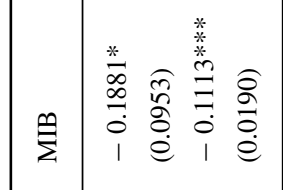
(*)

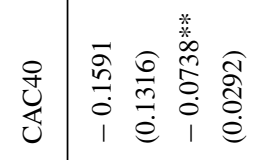

절

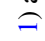

迆

욜

ت্

蹇

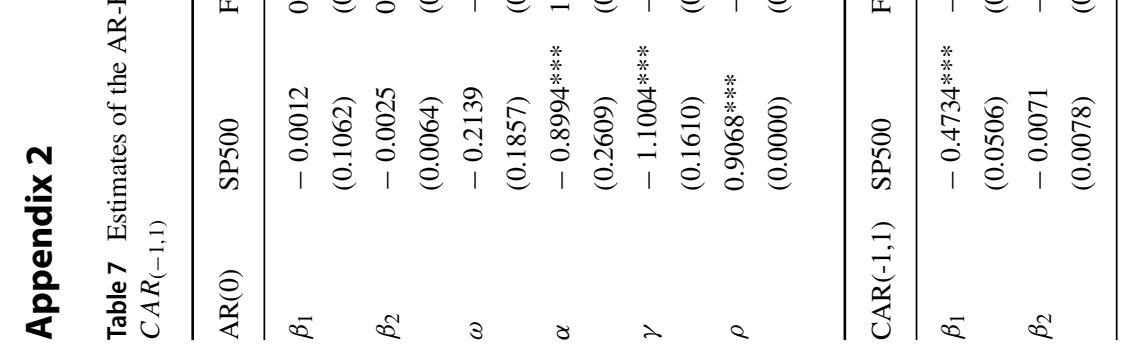




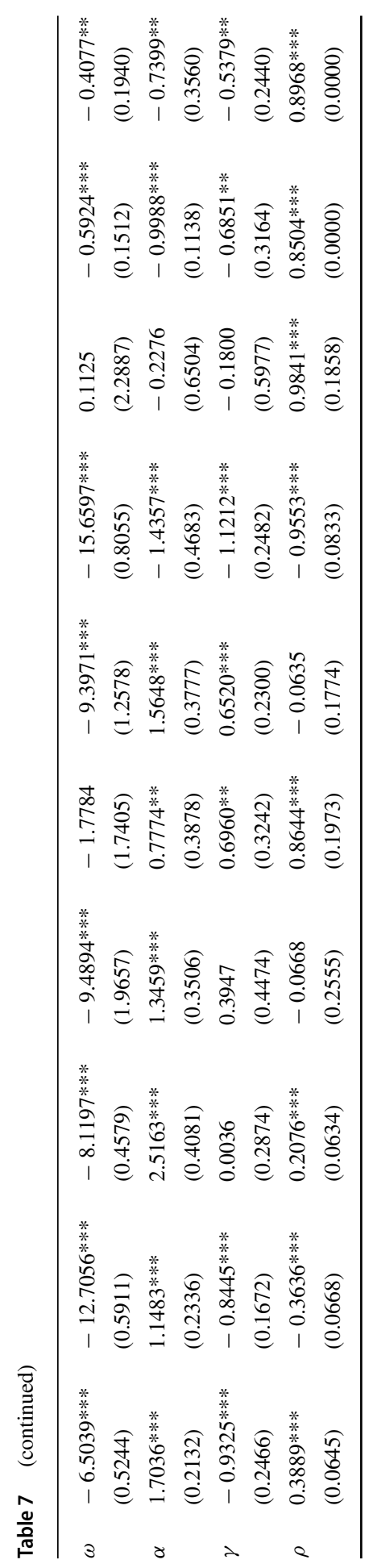




\section{References}

Aharon DY, Qadan M (2019) Bitcoin and the day-of-the-week effect. Finance Res Lett 31

Akhtaruzzaman M, Boubaker S, Sensoy A (2021) Financial contagion during covid-19 crisis. Finance Res Lett 38:101604

Albulescu C (2020) Coronavirus and financial volatility: 40 days of fasting and fear. arXiv:2003.04005

Alfarano S, Camacho E, Tedeschi G (2019) Alternative approaches for the reformulation of economics. J Econ Interact Coord 14:1-6

Alos E, Mancino ME, Merino R, Sanfelici S (2020) A fractional model for the covid-19 pandemic: Application to italian data. arXiv:2008.00033 (q-bio)

Baldwin R, di Mauro BW (2020) Mitigating the covid economic crisis: Act fast and do whatever it takes. VoxEu.org, CEPR

Bargigli L, Tedeschi G (2014) Interaction in agent-based economics: a survey on the network approach. Phys. A 399:1-15

Brockmann D, Helbing D (2013) The hidden geometry of complex, network-driven contagion phenomena. Science 342:1337-1342

Brown RB (2020) Public health lessons learned from biases in coronavirus mortality overestimation. Disaster Med Public Health Prepared 14(3):364-371

Buscema PM, Della Torre F, Breda M, Massini G, Grossi E (2020) Covid-19 in Italy and extreme data mining. Physica A Stat Mechan Appl 557:124991

Caferra R, Vidal-Tomás D (2021) Who raised from the abyss? a comparison between cryptocurrency and stock market dynamics during the covid-19 pandemic. Finance Research Letters, page 101954

Chatfield C (1994) 3. random process models. Methods Exp Phys 28:63-92

Chen L, Lu H, Yang L (2013) Investor sentiment, disagreement, and the breadth-return relationship. Manag Sci 59:1076-1091

Collard F, Hellwing C, Assenza T, Kankanamge S, Dupaigne M, Werquin N, Feve P (2020) The hammer and the dance: equilibrium and optimal policy during a pandemic crisis. CEPR, Discussion Paper, $\mathrm{N}$. DP14731, 2020

Conlon T, McGee R (2020) Safe haven or risky hazard? bitcoin during the covid-19 bear market. Finance Research Letters, page 101607

Cont R (2001) Empirical properties of asset returns: stylized facts and statistical issues. Quant Finance $1(2): 223-236$

Corbet S, Larkin C, Lucey B (2020) The contagion effects of the covid-19 pandemic: Evidence from gold and cryptocurrencies. Finance Research Letters, page 101554

Donadelli M, Kizys R, Riedel M (2016) Dangerous infectious diseases: Bad news for main street, good news for wall street? J. Financ. Mark. 35

Fama EF (1965) The behavior of stock-market prices. J Business 38(1):34-105

Giudice A, Paltrinieri A (2017) The impact of the arab spring and the ebola outbreak on african equity mutual fund investor decisions. Research in International Business and Finance 41

Gormsen NJ, Koijen RS (2020) Coronavirus: Impact on stock prices and growth expectations. University of Chicago, Becker Friedman Institute for Economics Working Paper, (2020-22)

Grilli R, Tedeschi G, Gallegati M (2020) Business fluctuations in a behavioral switching model: Gridlock effects and credit crunch phenomena in financial networks. Journal of Economic Dynamics \& Control 114

Hanna D, Huang Y (2004) The impact of sars on asian economies. Asian Economic Papers 3(1):102-112

Hansen PR, Lunde A (2005) A forecast comparison of volatility models: does anything beat a garch (1, 1)? J Appl Econom 20(7):873-889

Haug N, Geyrhofer L, Londei A, Dervic E, Desvars-Larrive A, Loreto V, Pinior B, Thurner S, Klimek P (2020) Ranking the effectiveness of worldwide covid-19 government interventions. Nat Human Behav 4(12):1303-1312

Iacobucci G (2020) Covid-19: Lack of capacity led to halting of community testing in march, admits deputy chief medical officer

Karafiath I (1988) Using dummy variables in the event methodology. FinanRev 23(3):351-357

Kingsly K, Henri K (2020) Central banks respond to covid-19 to stave off a financial crisis, they need for targeted fiscal measures should not be understated. They Need for Targeted Fiscal Measures Should not Be Understated (March 27, 2020) 
Kraemer MUG, Yang C-H, Gutierrez B, Wu C-H, Klein B, Pigott DM, du Plessis L, Faria NR, Li R, Hanage WP, Brownstein JS, Layan M, Vespignani A, Tian H, Dye C, Pybus OG, Scarpino S (2020) The effect of human mobility and control measures on the covid-19 epidemic in china. Science 368:493-497

Lee K.-B., Han S, Jeong Y (2020) Covid-19, flattening the curve, and benford's law. Physica A Stat Mechan Appl 559:125090

Malik F (2011) Estimating the impact of good news on stock market volatility. Appl Financ Econ 21(8):545-554

McKibbin WJ, Fernando R (2020) The global macroeconomic impacts of covid-19: Seven scenarios

Peckham R (2013a) Contagion: epidemiological models and financial crises. J Public Health 36(1):13-17

Peckham R (2013b) Economies of contagion: financial crisis and pandemic. Econ Soc 42(2):226-248

Pericoli M, Sbracia M (2003) A primer on financial contagion. J Econ Surv 17:571-608

Ramelli S, Wagner AF (2020) Feverish stock price reactions to covid-19

Riccetti L, Russo A, Gallegati M (2016) Stock market dynamics, leveraged network-based financial accelerator and monetary policy. Int Rev Econ Fin 43:509-524

Saunders A, Cornett M (2014) Financial markets and institutions. A modern perspective. McGrawHill/Irwin, New York

Shen J, Zheng B (2009) Cross-correlation in financial dynamics. EPL (Europhysics Letters) 86(4):48005

Taleb NN (2007) The black swan. The impact of the highly improbable

Tedeschi G, Caccioli F, Recchioni M (2020) Taming financial systemic risk: models, instruments and early warning indicators. J Econ Interact Coord 15:1-7

Tedeschi G, Iori G, Gallegati M (2009) The role of communication and imitation in limit order markets. Eur Phys J B 71:489

Vidal-Tomás D, Ibañez A (2018) Semi-strong efficiency of bitcoin. Finance Res Lett 27:259-265

Woolf SH, Chapman DA, Sabo RT, Weinberger DM, Hill L (2020) Excess deaths from covid-19 and other causes, march-april 2020. Jama 324(5):510-513

Wurgler J, Baker M (2007) Investor sentiment in the stock market. J Econ Perspect 21:129-152

Zaremba A, Kizys R, Aharon DY, Demir E (2020) Infected markets: Novel coronavirus, government interventions, and stock return volatility around the globe. Finance Research Letters, page 101597

Publisher's note Springer Nature remains neutral with regard to jurisdictional claims in published maps and institutional affiliations. 